\title{
Gas Diffusion Layers in Fuel Cells and Electrolysers: A Novel Semi-Empirical Model to Predict Electrical Conductivity of Sintered Metal Fibres
}

\author{
Reza Omrani and Bahman Shabani * \\ School of Engineering, RMIT University, Bundoora East Campus, Melbourne 3083, Australia; \\ reza.omrani@rmit.edu.au \\ * Correspondence: bahman.shabani@rmit.edu.au; Tel.: +61-3-9925-4353
}

Received: 21 December 2018; Accepted: 27 February 2019; Published: 5 March 2019

check for updates

\begin{abstract}
This paper introduces novel empirical as well as modified models to predict the electrical conductivity of sintered metal fibres and closed-cell foams. These models provide a significant improvement over the existing models and reduce the maximum relative error from as high as just over $30 \%$ down to about $10 \%$. Also, it is shown that these models provide a noticeable improvement for closed-cell metal foams. However, the estimation of electrical conductivity of open-cell metal foams was improved marginally over previous models. Sintered porous metals are widely used in electrochemical devices such as water electrolysers, unitised regenerative fuel cells (URFCs) as gas diffusion layers (GDLs), and batteries. Having a more accurate prediction of electrical conductivity based on variation by porosity helps in better modelling of such devices and hence achieving improved designs. The models presented in this paper are fitted to the experimental results in order to highlight the difference between the conductivity of sintered metal fibres and metal foams. It is shown that the critical porosity (maximum achievable porosity) can play an important role in sintered metal fibres to predict the electrical conductivity whereas its effect is not significant in open-cell metal foams. Based on the models, the electrical conductivity reaches zero value at $95 \%$ porosity rather than $100 \%$ for sintered metal fibres.
\end{abstract}

Keywords: porous metal; porosity; sintered metal fibre; metal foam; electrical conductivity; electrochemical; fuel cell

\section{Introduction}

In recent decades, the development and use of porous metals in different engineering applications have increased substantially. Thanks to their highly practical characteristics, on top of bulk metals properties, these types of materials have functional and structural applications in a wide range of industries such as energy transportation and biomedical applications [1,2]. The main characteristics of porous metals are: low density, high permeability in open structures, high energy absorption and large specific surface area [1,3]. These properties that are linked with good electrical and thermal conductivity, corrosion resistance (when corrosion resistive metals such as titanium and stainless steel are used), and even distribution of the fluids, make them very attractive for electrochemical energy conversion devices [1,4]. For example, they are widely used as electrodes in batteries [1], gas diffusion layer (GDL) [4-6] or flow-field [7,8] in electrolysers, fuel cells and unitised regenerative fuel cells (URFCs). They can be either in the form of metal foams, sintered metallic powders/fibres or mesh.

Metal foams, commonly $\mathrm{Ni}, \mathrm{Pb}$ and $\mathrm{Cu}$, are mostly used as electrodes in batteries [9]; $\mathrm{Ni}$ foam has also been used in fuel cells as flow field [10,11]. Sintered metal powders/fibres (Figure 1) are commonly used as GDLs in polymer electrolyte membrane (PEM) and solid oxide (SO) electrolysers 
or URFCs $[9,10]$ instead of carbon-based GDLs that usually corrode rapidly in such hydrated environments. Sintered metal fibres or powders are of particularly high interest due to their strong mechanical properties that make them suitable for providing mechanical support for other components in applications such as high-pressure water electrolysis $[6,9,12]$. Sintered metal powders provide porosities lower than $50 \%[13,14]$, which is suitable for electrolyser applications [15]; on the other hand, sintered metal fibres can provide porosities higher than $50 \%$ that is suitable for applications such as PEMFCs or URFCs [16,17]. In these kinds of applications, the electrical conductivity plays a major role in the performance as higher conductivity translates into lower ohmic losses, and hence higher efficiency.

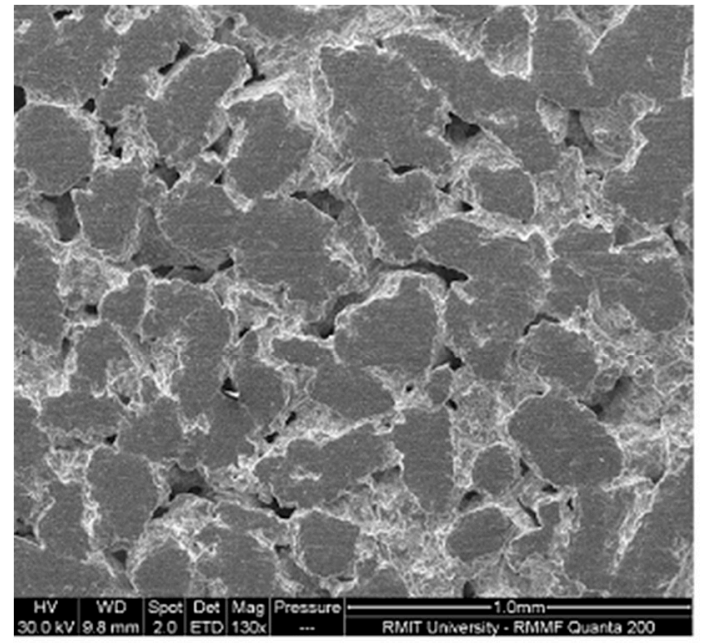

(A)

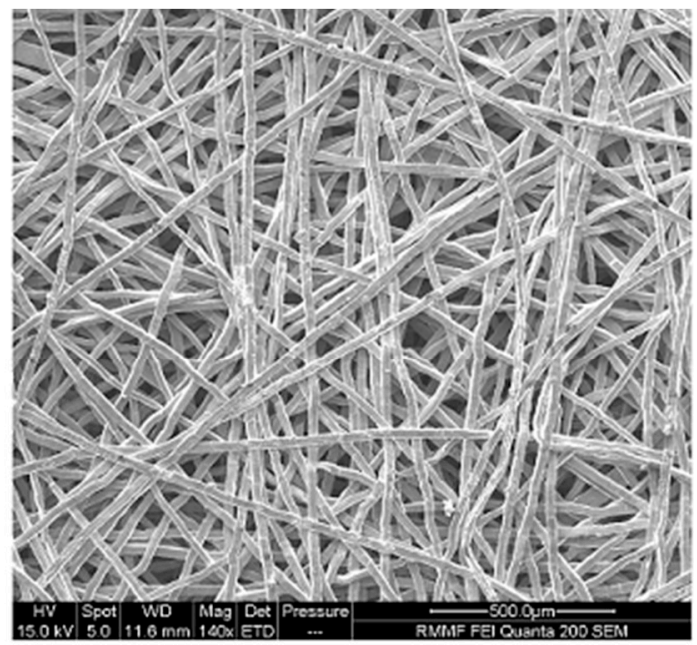

(B)

Figure 1. SEM images of sintered titanium powder (A) and sintered titanium fibre (B) commonly used as a gas diffusion layer (GDL) in unitised regenerative fuel cells (URFCs) and electrolysers.

In electrochemical applications, high electrical conductivity is preferable that is required for transferring the electrons effectively and hence, achieving higher efficiency. The electrical resistance of the porous metal (i.e., electrode) contributes to the ohmic losses. The electrical resistance of a porous metal increases by increasing its porosity; however, in many applications such as fuel cells, higher porosities are favourable for better delivery of reactants to the active area [17-23]. Therefore, the optimal porosity is a trade-off between the electrical conductivity and the species transport properties [18,24]. There are not many experimental data reported on the impact of GDL's porosity on the performance of fuel cells or other similar devices. Many conventional fuel cells use carbon-based GDL and such materials do not give enough control over parameters such as pore size and porosity. In addition, as these GDLs are compressible, the in-situ porosities are different from the ex-situ porosities, and they are significantly affected by the assembly pressure [25-27]. However, in URFCs and electrolysers, this issue does not exist as porous metallic GDLs are used with higher mechanical strength. Therefore, the in-situ properties of these GDLs remain almost similar to ex-situ properties, and they also give more opportunity to control different properties of the GDL and experimentally study their individual effect on the electrochemical device performance in a more controlled fashion.

Despite this fact, the variation of electrical conductivity with porosity is neglected in many simulations $[20-22,28,29]$ as there are not reliable models to predict this property for fibrous materials and hence usually a constant value is considered. Therefore, it is of great importance to have models capable of predicting the electrical conductivity of porous metals, especially sintered porous metals, in order to perform more accurate simulations to predict the performance of electrochemical devices. Such a model can help determine the effect of parameters such as porosity of the porous electrode (e.g., in fuel cells, electrolysers, URFCs and batteries). 
The electrical conductivity of porous metals is considerably lower than the bulk material in high porosity ranges. For example, based on measurements of electrical conductivity of aluminium foam by Feng et al. [30], the electrical conductivity at $70.5 \%$ and $86.7 \%$ porosity is approximately $1.708 \times 10^{6} \mathrm{~m}^{-1}$ and $0.5 \times 10^{6} \mathrm{~S} \cdot \mathrm{m}^{-1}$, respectively, compared to $3.69 \times 10^{7} \mathrm{~S} \cdot \mathrm{m}^{-1}$ for aluminium. As a result, the electrical resistance of GDL increases rapidly at high porosities, which in turn translates into ohmic losses [31,32].

Several researchers have aimed to provide empirical relationships to link the electrical conductivity of the porous metal materials with the properties of the bulk metal and its porosity $[30,33,34]$ or pore structure [35,36]. Feng et al. [30] have suggested a simplified model based on the model proposed by Huang [37]. Liu et al. [34,38,39] also conducted a series of experiments to determine the electrical resistivity of nickel foams developed by electroplating on the polyether sponge sheet using a double circuit bridge. They proposed a physical model for high porosity metal foams.

However, these formulas have been developed based on metal foams and their applicability for sintered metal fibres remains questionable. In these formulas (presented in Section 2.2), the porous metal electrical conductivity becomes zero when the porosity is $100 \%$ that cannot happen physically for sintered fibres or powders. High porosities close to $100 \%$ can be achieved in open-cell metal foams. However, in porous metals produced by sintering powders or fibres, the initial or maximum porosity (i.e., tap porosity before sintering) is lower than $100 \%$ (it can be increased by methods such as using pore-formers). Zhou et al. [40] have examined the applicability of three models, Equations (2)-(4), for sintered metal fibres; they have reported that these models, which are proposed for metal foams, cannot predict the results accurately as errors of more than $30 \%$ were observed. The electrical conductivity of sintered porous metals depends on several factors and the complex interaction between them such as impurities, manufacturing method, temperature, pressure and duration. The work of carried out by Sheng et al. [41] and Huang et al. [42] on thermal conductivity (analogous to electrical conductivity) of sintered metal fibres, highlights the complexity and difficulty in prediction of electrical conductivity of such products. It highlights the fact that there is a need for fitting parameters, detailed microstructural analysis [42], or reliance of measurement of other properties of the sintered metals (e.g., measurement of electrical conductivity to assist with the prediction of thermal conductivity [41]) to estimate the desired characteristic.

Accordingly, in this paper, it will be investigated whether the models can be improved to predict the electrical conductivity of sintered metal fibres with less error. The models analysed by Zhou et al. [40], are fitted to different experimental results from literature; they are modified considering the critical porosity to achieve higher accuracy. Also, two new models are presented for sintered metal fibres to improve the estimation of electrical conductivity. These models are also shown to improve the estimation of the electrical conductivity of closed-cell metal foams.

\section{Method}

\subsection{Factors Affecting Electrical Conductivity of Porous Metals}

Most of the models used for predicting the electrical conductivity of porous media are a function of porosity. Pore size has been shown to have a negligible effect on electrical conductivity $[30,36,40,43]$. Feng et al. [30] have analysed aluminium foams with pore diameters of 1.7, 2.5 and $3.6 \mathrm{~mm}$ and have reported a negligible difference between them. Zhou et al. [40] have analysed sintered copper fibres and have suggested that pore size has a minor effect on the electrical conductivity. Similarly, Goodall et al. [43] have reported no effect of pore size on the electrical conductivity of open cell aluminium foams; they have measured the electrical conductivity of aluminium foams with pore sizes of $75 \mu \mathrm{m}$ and $400 \mu \mathrm{m}$ with porosities between $64 \%$ and $93 \%$. Hakamada et al. [36] have investigated the effect of pore size on electrical conductivity of porous aluminium (Figure 2): for the range that they have considered (i.e., from 212-300 to 850-1000 $\mu \mathrm{m}$ ) the effect of pore size on electrical conductivity was found to be negligible, especially with pore sizes smaller than $600 \mu \mathrm{m}$. 


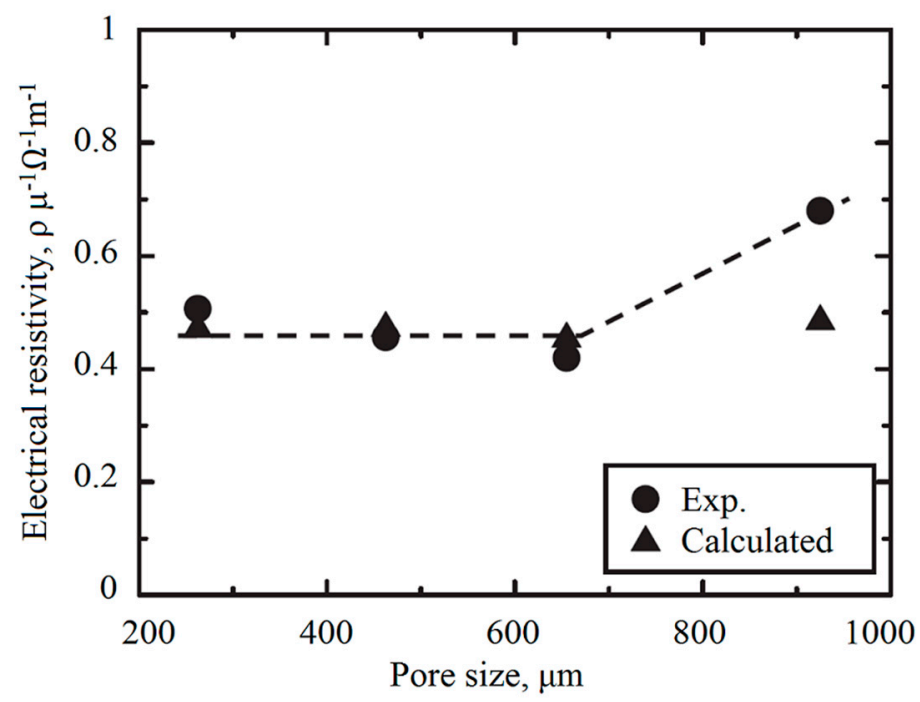

Figure 2. Effect of pore size on the electrical conductivity of porous aluminium with $80 \%$ porosity [36].

Some researchers have tried to predict the electrical conductivity according to the pore size and structure for porous metals [36]. Hakamada et al. [36] investigated porous aluminium produced by powder metallurgy and using spacers. They considered samples with a porosity of $77-90 \%$ and a pore diameter of 212-300 to $850-1000 \mu \mathrm{m}$. They proposed a model based on the porosity, pore size, and the size of openings in the cells. The model is in good agreement with the experimental results except for the pore size of $925 \mu \mathrm{m}$ for which the model underestimates the experimental value by almost $30 \%$ and hence the range of its applicability should be investigated further. This model, however, can be used mainly for porous metals with controlled pore size and cannot be applied to samples with a range of random pore diameter.

As indicated by the literature the effect of pore size on electrical conductivity is negligible and this assumption offers more accuracy for pore sizes of lower than $100 \mu \mathrm{m}$ (e.g., used in GDLs for fuel cell applications). Hence the focus of the models to be discussed in this paper is mainly on the effect of porosity (i.e., on electrical conductivity). In addition, models which are based on porosity can be easily applied to different samples without worrying about the pore size.

\subsection{Porous Metal Electrical Conductivity Models}

Several semi-empirical models have been proposed to estimate the electrical conductivity based on the conductivity of the bulk material and the porosity of porous metals [30,33,34]. Langlois and Coeuret [33] have proposed the following formula for highly porous metal foams:

$$
\sigma=\frac{1-\varepsilon}{4} \sigma_{0}
$$

In this equation, $\sigma$ is the electrical conductivity of the porous metal, $\varepsilon$ is the porosity, and $\sigma_{0}$ is the conductivity of the bulk metal, which in this case is the metal. This model has been proposed based on the measurements of electrical conductivity of nickel foams with porosities in a very narrow range: $97.0 \%$ to $97.8 \%$. This model is only applicable to the nickel foams with porosities in the aforementioned range which are made with specific conditions. Different manufacturing conditions and also defects in the samples can affect the electrical conductivity of porous metals $[30,40]$. In order to include these effects, Liu et al. [34,39] modified the Langlois and Coeuret formula by introducing a coefficient, $K$ :

$$
\sigma=K \frac{1-\varepsilon}{4} \cdot \sigma_{0}
$$


$K$ represents the effect of different manufacturing methods and parameters, defects and dimensional variation of cells or particles and other possible factors affecting the electrical conductivity of a porous metal which results in deviation from theory. Its value is found through curve fitting to the measured data. They have shown that Equation (1) used for nickel foams with a porosity between $88 \%$ and $99 \%$ results in absolute relative errors (ARE) from $40 \%$ to $17 \%$, respectively. It can be observed that as the porosity decreases the error of Equation (1) increases, whereas the maximum ARE from Equation (2) is $16.1 \%$ at $98.84 \%$ porosity.

Liu et al. $[34,39]$ have also proposed a physical model based on the octahedron theoretical model for highly porous metal foams with porosities higher than $90 \%$ :

$$
\sigma=K \frac{1-\varepsilon}{3\left[1-0.121 \cdot(1-\varepsilon)^{1 / 2}\right]} \cdot \sigma_{0}
$$

For the same range, this model has better accuracy and the maximum ARE is $14.9 \%$. Both of these models have higher errors at higher porosities. This will be discussed further in Section 3.

Feng et al. [30] have proposed the following formula for calculating the electrical conductivity of closed cell metal foams:

$$
\sigma=\frac{2 K(1-\varepsilon)}{2 K+\varepsilon} \cdot \sigma_{0}
$$

For spherical cells $K$ has been suggested to be around 0.3 .

Zhou et al. [40] have used the three models suggested by Liu et al. [34] and Feng et al. [30] for sintered copper fibres with porosities between $70 \%$ to $90 \%$. The relative absolute error of the models for some points is as high as $30 \%$ (Table 1 ). 
Table 1. Experimental data from Zhou et al. [40] and calculated values of electrical conductivity of sintered copper fibres using different models.

\begin{tabular}{|c|c|c|c|c|c|c|c|c|c|c|c|c|c|}
\hline \multirow{3}{*}{ Porosity } & \multicolumn{7}{|c|}{ Electrical Conductivity $\left(106 \mathrm{~S} \cdot \mathrm{m}^{-1}\right)$} & \multicolumn{6}{|c|}{ Absolute Relative Error } \\
\hline & \multirow{2}{*}{ Exp. } & \multicolumn{2}{|c|}{ Equation (2) } & \multicolumn{2}{|c|}{ Equation (3) } & \multicolumn{2}{|c|}{ Equation (4) } & \multicolumn{2}{|c|}{ Equation (2) } & \multicolumn{2}{|c|}{ Equation (3) } & \multicolumn{2}{|c|}{ Equation (4) } \\
\hline & & Original & Equation (5) & Original & Equation (6) & Original & Equation (7) & Original & Equation (5) & Original & Equation (6) & Original & Equation (7) \\
\hline $70 \%$ & 0.291 & 0.216 & 0.286 & 0.247 & 0.291 & 0.219 & 0.287 & $26 \%$ & $2 \%$ & $15 \%$ & $0 \%$ & $25 \%$ & $1 \%$ \\
\hline $75 \%$ & 0.228 & 0.180 & 0.228 & 0.192 & 0.220 & 0.181 & 0.228 & $21 \%$ & $0 \%$ & $16 \%$ & $3 \%$ & $21 \%$ & $0 \%$ \\
\hline $80 \%$ & 0.144 & 0.144 & 0.170 & 0.144 & 0.158 & 0.144 & 0.170 & $0 \%$ & $18 \%$ & $0 \%$ & $10 \%$ & $0 \%$ & $18 \%$ \\
\hline $85 \%$ & 0.102 & 0.108 & 0.113 & 0.102 & 0.103 & 0.107 & 0.112 & $6 \%$ & $10 \%$ & $0 \%$ & $1 \%$ & $5 \%$ & $10 \%$ \\
\hline $90 \%$ & 0.055 & 0.072 & 0.055 & 0.064 & 0.054 & 0.071 & 0.055 & $31 \%$ & $0 \%$ & $17 \%$ & $2 \%$ & $29 \%$ & $0 \%$ \\
\hline
\end{tabular}




\section{Improvement of the Existing Models}

The discussed models in Section 2 predict that conductivity becomes zero when the porosity is $100 \%$. In order to have electrical conductivity in a porous media, a connected solid phase is required. As can be seen in Figure 1, a porous metal is formed by randomly distributed pores of different sizes, which are formed by the surrounding complicated metallic structure (i.e., infinite cluster). The integrity of the porous metal relies on the existence of such a cluster. In the absence of a continuous cluster, the effective electrical conductivity and other properties become zero. Consequently, conductivity can become zero at porosities lower than $100 \%$, which is the critical porosity for electrical conductivity or structural integrity. If the models are modified by introducing $\varepsilon_{\mathcal{c}}$ as the critical porosity, the models proposed by [34] and [30] will be as follows:

$$
\begin{gathered}
\sigma=K \frac{1-\varepsilon / \varepsilon_{\mathcal{c}}}{4} \cdot \sigma_{0} \\
\sigma=K \frac{1-\varepsilon / \varepsilon_{\mathcal{c}}}{3\left[1-0.121 \cdot(1-\varepsilon)^{1 / 2}\right]} \cdot \sigma_{0} \\
\sigma=\frac{2 K\left(1-\varepsilon / \varepsilon_{\mathcal{c}}\right)}{2 K+\varepsilon} \cdot \sigma_{0}
\end{gathered}
$$

In these equations, the electrical conductivity will be zero when porosity is equal to the critical porosity, $\varepsilon_{c}$. These models are fitted to the experimental data from Feng et al. [30], Zhou et al. [40] and Liu et al. [34]. Feng et al. [30] have measured the electrical conductivity of closed-cell Al-alloy foams; Zhou et al. [40] have reported the electrical conductivity of sintered copper fibres; and Liu et al. [34] have investigated the electrical conductivity of open-cell nickel foams. It is expected that closed-cell foams have a lower critical porosity compared to open-cell foams. The reason is that more solid phase metal is required to form the structure of close-cell foams compared to that needed in open-cell porous metals.

Table 1 presents the experimental measurement of Zhou et al. [34] with the original equations and the modified models. The data are presented in Figure 3.

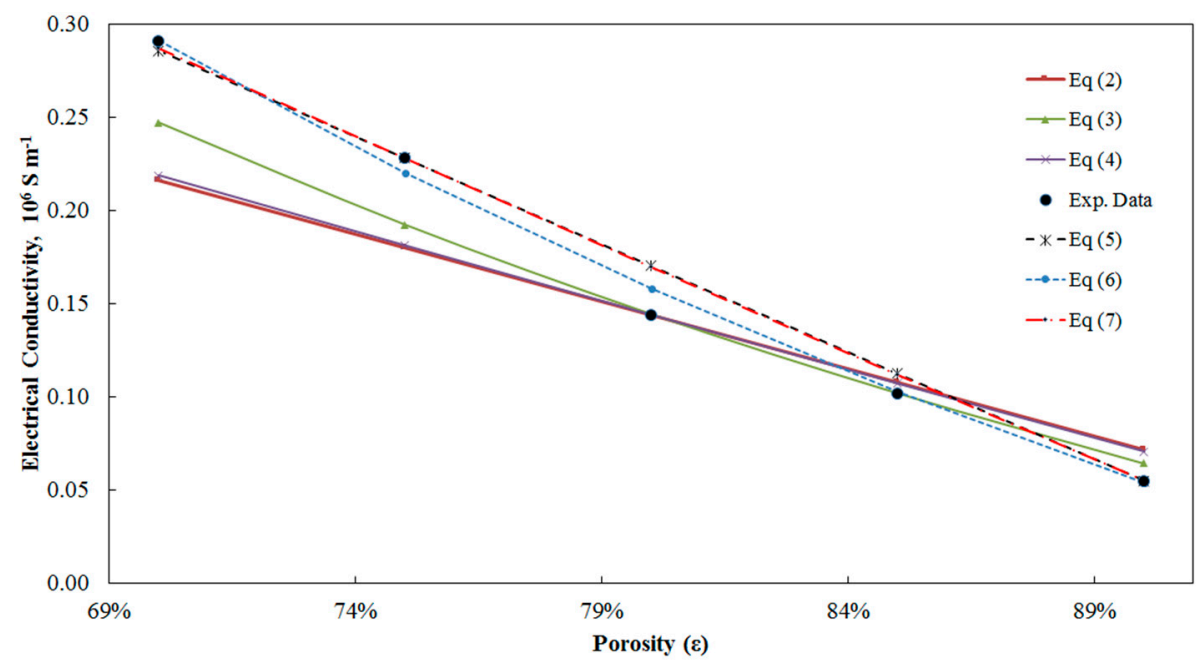

Figure 3. Different models fitted to experimental data from Zhou et al. [40].

As it can be seen in Table 1, the modified models result in considerably less error. The maximum ARE for Equations (5)-(7) is $18 \%, 10 \%$ and $18 \%$, respectively, compared to $31 \%, 17 \%$ and $29 \%$ for Equations (2)-(4). The values of critical porosity for different models are calculated by fitting the models to the experimental data through minimising the ARE. The critical porosity for Equations (5)-(7) is $0.948,0.962$ and 0.949 , respectively. 
The critical porosity for the three fitted models is around 95\% that is consistent with what is expected in reality. Equation (2) and its modified version, Equation (5), are presented against the experimental data from Feng et al. [30] in Figure 4. From this figure, it is evident that the experimental data do not approach zero conductivity at $100 \%$ porosity. The presumption of having zero conductivity and $100 \%$ porosity results in substantial errors and does not reflect an accurate relation between porosity and electrical conductivity.

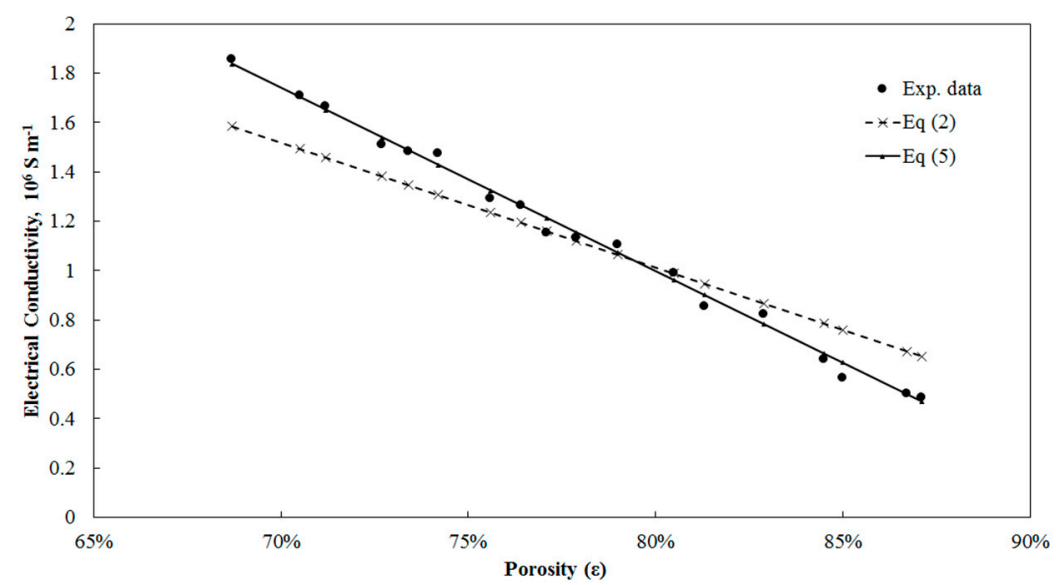

Figure 4. Prediction of experimental data from Feng et al. [30] by Equation (2) and its modified version, Equation (5).

Also, the models have been fitted to Feng et al. [30] measurements (Table 2) and a significant improvement has been observed. The maximum ARE has reduced from 35\%, 26\% and $34 \%$ for Equations (2)-(4), respectively, to $11 \%, 9 \%$ and $11 \%$ for Equations (5)-(7), respectively. Similarly, the average ARE has reduced from $13 \%, 7 \%$ and $12 \%$ to $3 \%$ for the modified models. From these results, it can be concluded that Equations (2)-(4) are not able to estimate the electrical conductivity at high porosities and considerable deviation can be observed. By introducing the critical porosity, the models perform significantly better. Therefore, it is concluded that the assumption of having zero electrical conductivity at $100 \%$ porosity or zero relative density cannot be valid. After fitting the models to these data, the critical porosity is $94 \%$ for Equations (5) and (7) and 95\% for Equation (6).

The models were fitted to the experimental data from Liu et al. [34] that are presented in Figure 5. The models and their modified versions perform almost the same. The maximum ARE is between $12 \%$ and $17 \%$ for all models and the average ARE is between $5.5 \%$ and $8.2 \%$. As it was expected, the critical porosity calculated from the modified models for these data was very close to 1 as the samples had an open-cell structure. The calculated critical porosity after fitting the models to the data was $99.7 \%$ for Equations (5) and (7) and $99.8 \%$ for Equation (6). As the critical porosity is close to unity, the improvement of the models is not significant. 
Table 2. Experimental data from Feng et al. [30] and calculated values of electrical conductivity of Al-alloy foams using different models.

\begin{tabular}{|c|c|c|c|c|c|c|c|c|c|c|c|c|c|}
\hline \multirow{3}{*}{ Porosity } & \multicolumn{7}{|c|}{ Electrical Conductivity $\left(10^{6} \mathrm{~S} \mathrm{~m}^{-1}\right)$} & \multicolumn{6}{|c|}{ Absolute Relative Error } \\
\hline & \multirow{2}{*}{ Exp. } & \multicolumn{2}{|c|}{ Equation (2) } & \multicolumn{2}{|c|}{ Equation (3) } & \multicolumn{2}{|c|}{ Equation (4) } & \multicolumn{2}{|c|}{ Equation (2) } & \multicolumn{2}{|c|}{ Equation (3) } & \multicolumn{2}{|c|}{ Equation (4) } \\
\hline & & Original & Equation (5) & Original & Equation (6) & Original & Equation (7) & Original & Equation (5) & Original & Equation (6) & Original & Equation (7) \\
\hline 0.687 & 1.855 & 1.586 & 1.837 & 1.809 & 1.896 & 1.610 & 1.845 & $15 \%$ & $1 \%$ & $2 \%$ & $2 \%$ & $13 \%$ & $1 \%$ \\
\hline 0.705 & 1.708 & 1.495 & 1.703 & 1.666 & 1.727 & 1.514 & 1.708 & $12 \%$ & $0 \%$ & $2 \%$ & $1 \%$ & $11 \%$ & $0 \%$ \\
\hline 0.712 & 1.664 & 1.459 & 1.651 & 1.612 & 1.664 & 1.477 & 1.655 & $12 \%$ & $1 \%$ & $3 \%$ & $0 \%$ & $11 \%$ & $1 \%$ \\
\hline 0.727 & 1.511 & 1.383 & 1.540 & 1.499 & 1.532 & 1.398 & 1.541 & $8 \%$ & $2 \%$ & $1 \%$ & $1 \%$ & $8 \%$ & $2 \%$ \\
\hline 0.734 & 1.482 & 1.348 & 1.488 & 1.448 & 1.472 & 1.361 & 1.488 & $9 \%$ & $0 \%$ & $2 \%$ & $1 \%$ & $8 \%$ & $0 \%$ \\
\hline 0.742 & 1.474 & 1.307 & 1.429 & 1.391 & 1.404 & 1.318 & 1.428 & $11 \%$ & $3 \%$ & $6 \%$ & $5 \%$ & $11 \%$ & $3 \%$ \\
\hline 0.756 & 1.293 & 1.236 & 1.325 & 1.293 & 1.290 & 1.245 & 1.323 & $4 \%$ & $2 \%$ & $0 \%$ & $0 \%$ & $4 \%$ & $2 \%$ \\
\hline 0.764 & 1.265 & 1.196 & 1.265 & 1.239 & 1.226 & 1.203 & 1.263 & $5 \%$ & $0 \%$ & $2 \%$ & $3 \%$ & $5 \%$ & $0 \%$ \\
\hline 0.771 & 1.153 & 1.160 & 1.213 & 1.192 & 1.171 & 1.166 & 1.210 & $1 \%$ & $5 \%$ & $3 \%$ & $2 \%$ & $1 \%$ & $5 \%$ \\
\hline 0.779 & 1.131 & 1.120 & 1.154 & 1.140 & 1.109 & 1.124 & 1.151 & $1 \%$ & $2 \%$ & $1 \%$ & $2 \%$ & $1 \%$ & $2 \%$ \\
\hline 0.79 & 1.106 & 1.064 & 1.072 & 1.069 & 1.026 & 1.066 & 1.068 & $4 \%$ & $3 \%$ & $3 \%$ & $7 \%$ & $4 \%$ & $3 \%$ \\
\hline 0.805 & 0.988 & 0.988 & 0.961 & 0.976 & 0.917 & 0.988 & 0.957 & $0 \%$ & $3 \%$ & $1 \%$ & $7 \%$ & $0 \%$ & $3 \%$ \\
\hline 0.813 & 0.853 & 0.947 & 0.901 & 0.927 & 0.860 & 0.946 & 0.897 & $11 \%$ & $6 \%$ & $9 \%$ & $1 \%$ & $11 \%$ & $5 \%$ \\
\hline 0.829 & 0.822 & 0.866 & 0.782 & 0.833 & 0.749 & 0.863 & 0.779 & $5 \%$ & $5 \%$ & $1 \%$ & $9 \%$ & $5 \%$ & $5 \%$ \\
\hline 0.845 & 0.639 & 0.785 & 0.663 & 0.742 & 0.642 & 0.781 & 0.661 & $23 \%$ & $4 \%$ & $16 \%$ & $0 \%$ & $22 \%$ & $3 \%$ \\
\hline 0.85 & 0.565 & 0.760 & 0.626 & 0.714 & 0.609 & 0.755 & 0.624 & $35 \%$ & $11 \%$ & $26 \%$ & $8 \%$ & $34 \%$ & $11 \%$ \\
\hline 0.867 & 0.500 & 0.674 & 0.500 & 0.622 & 0.500 & 0.667 & 0.500 & $35 \%$ & $0 \%$ & $24 \%$ & $0 \%$ & $33 \%$ & $0 \%$ \\
\hline 0.871 & 0.486 & 0.654 & 0.470 & 0.600 & 0.475 & 0.647 & 0.471 & $34 \%$ & $3 \%$ & $24 \%$ & $2 \%$ & $33 \%$ & $3 \%$ \\
\hline
\end{tabular}




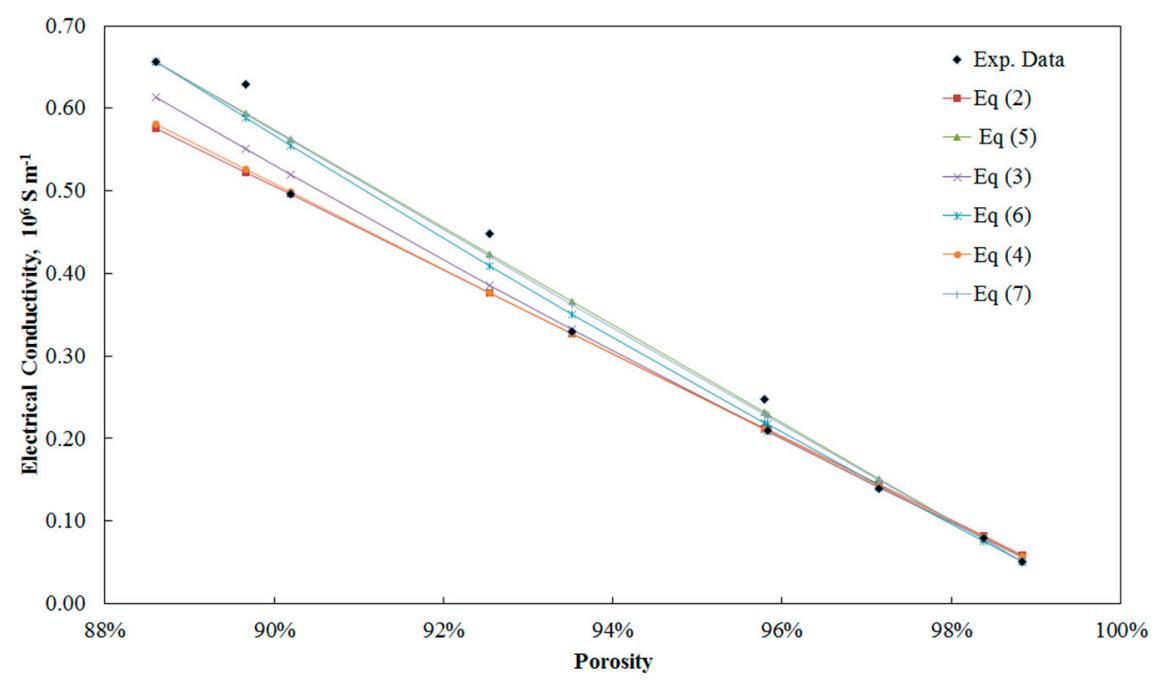

Figure 5. Fitting of different models to experimental data from Liu et al. [34].

\section{New empirical Models for Prediction of Electrical Conductivity of Porous Metals}

\subsection{An Overview}

As discussed, the existing models fail to give reliable predictions of electrical conductivity for sintered metal fibres and as can be seen in Section 3, errors can be as high as 30\%. Modified models improved the accuracy of the existing models. It was found out that the main reason for high inaccuracy is neglecting the critical porosity. In this section new models will be proposed to improve the accuracy of these existing models. The models will include the critical porosity as well as the tortuosity effect on electrical conductivity.

\subsection{Models to Predict Sintered Metal Fibres Electrical Conductivity}

In this section according to the rule of mixture, and considering the effect of tortuosity and critical porosity, two new models for predicting the electrical conductivity of porous materials are proposed. Based on the rule of mixture, the electrical conductivity of unidirectional metal fibres can be expressed as below [44]:

$$
\sigma=\varepsilon \sigma_{\text {air }}+(1-\varepsilon) \sigma_{s}
$$

Considering that the electrical conductivity of air is negligible compared to the conductivity of the solid metal phase, therefore the electrical conductivity can be expressed as:

$$
\sigma=\sigma_{s}(1-\varepsilon)
$$

Although this formula gives the correct value for long unidirectional fibres, this is not valid in sintered metal fibres as the length of the fibres can vary as well as their directions. Also, the connection of the fibres depends on the sintering conditions such as pressure, temperature, and duration [40]. For instance, Zhou et al. [40] have shown that for sintered copper fibres samples with a porosity of $90 \%$ porosity, the electrical conductivity at $1000{ }^{\circ} \mathrm{C}$ was almost 5.4 times as high as of the electrical conductivity at $700{ }^{\circ} \mathrm{C}$. Therefore, in order to introduce the effect of manufacturing processes, inhomogeneity in the structure, and possible defects we can introduce a coefficient that accounts for these effects:

$$
\sigma=K \sigma_{\mathcal{s}}(1-\varepsilon)
$$


It is expected that the value of $K$ to be lower than one (i.e., $K=1$ represents ideal conditions). Here the critical porosity, $\varepsilon_{\mathcal{C}}$, can be introduced to the previous equation:

$$
\sigma=K \sigma_{s}\left(1-\varepsilon / \varepsilon_{\mathcal{c}}\right)
$$

One factor that contributes to the increase of the conductivity in porous metals is the increase in the path that electrons need to travel, i.e., the electrical tortuosity, due to the presence of nonconductive voids. This is illustrated in Figure 6. It can be seen that the electrons have to travel a longer path in a porous metal in comparison to a bulk metal where they can travel in a straight line.

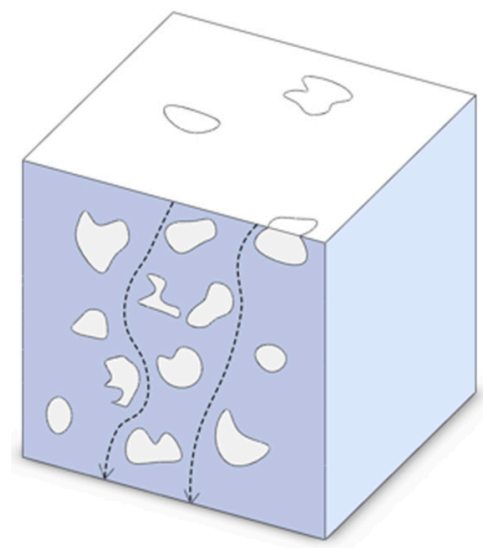

(A)

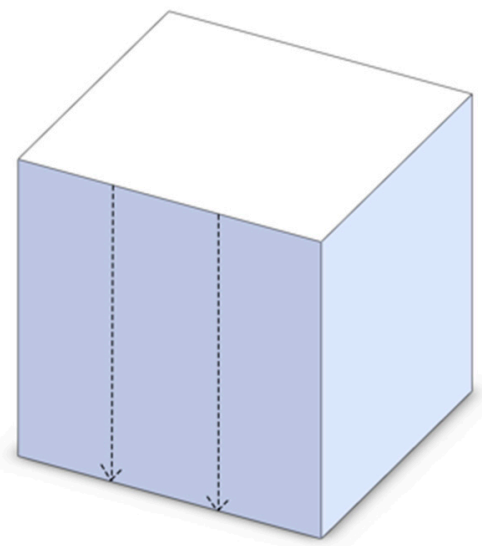

(B)

Figure 6. Electron path in (A) a porous and (B) a bulk metal.

This can be expressed by the tortuosity concept. If we assume in the bulk material, the length travelled by electrons is $L_{0}$ and in the porous material it is $L$, and consider $\tau$ as tortuosity, then we can write:

$$
L=\tau L_{0}
$$

This can also account for the fact that fibres are not unidirectional. The Bruggeman relation is a widely accepted estimation for tortuosity $[45,46]$ :

$$
\tau=\varepsilon^{-\alpha}
$$

However, this expression is hydraulic tortuosity in the void space in the porous media. $\alpha$ is a coefficient, which depends on the structure of the porous media. For the electric tortuosity, we can rewrite the Bruggeman relation as below as the solid phase is important:

$$
\tau=(1-\varepsilon)^{-\alpha}
$$

This relation satisfies the boundary conditions for tortuosity at $\varepsilon=0$ and $\varepsilon=1$. When porosity is equal to zero, the tortuosity must be 1 and when porosity is 1 , tortuosity must be $\infty$.

Another accepted model for tortuosity is [47]:

$$
\tau=1-P \ln (\varepsilon)
$$

Here, $\mathrm{P}$ is a fitting parameter that depends on the porous media structure and can be estimated experimentally or numerically, such as using lattice Boltzmann simulation. Again, to satisfy the following conditions: $\tau \rightarrow \infty$ when $\varepsilon=1$ and $\tau \rightarrow 1$ when $\varepsilon=0$, we can change the formula to:

$$
\tau=1-P \ln (1-\varepsilon)
$$


Now, by introducing the effect of tortuosity in Equation (10), we have:

$$
\sigma=K \sigma_{s}\left(1-\varepsilon / \varepsilon_{c}\right) \tau^{-1}
$$

By replacing tortuosity in Equation (17) by Equations (13) and (14) we have:

$$
\begin{gathered}
\sigma=K \sigma_{\mathcal{S}}\left(1-\varepsilon / \varepsilon_{\mathcal{c}}\right)(1-\varepsilon)^{\alpha} \\
\sigma=\frac{K \sigma_{\mathcal{S}}\left(1-\varepsilon / \varepsilon_{\mathcal{c}}\right)}{1-\operatorname{Pln}(\varepsilon)}
\end{gathered}
$$

The results for the two new models are presented in Table 3 for experimental data from Zhou et al. [40] and in Table 4, for data from Feng et al. [30]. These models result in lower ARE compared to previous models. The two new models have almost similar results. The ARE for different structures and using different models can be seen in Table 5. It is clear that for sintered metal fibres the accuracy of the models can be significantly improved by the critical porosity introduction; the improvement is less for closed-cell metal foam; for the open-cell foam the improvement is insignificant.

Table 3. Experimental data from Zhou et al. [40] and calculated values of electrical conductivity of sintered copper fibres using the newly proposed models.

\begin{tabular}{cccccc}
\hline \multirow{2}{*}{ Porosity } & \multicolumn{2}{c}{ Electrical Conductivity $\left.\mathbf{( 1 0}^{\mathbf{6}} \mathbf{S} \cdot \mathbf{m}^{-\mathbf{1}}\right)$} & \multicolumn{2}{c}{ Absolute Relative Error } \\
\cline { 2 - 6 } & Exp. & Equation (18) & Equation (19) & Equation (18) & Equation (19) \\
\hline $70 \%$ & 0.291 & 0.291 & 0.291 & $0.1 \%$ & $0.0 \%$ \\
$75 \%$ & 0.228 & 0.221 & 0.220 & $3.0 \%$ & $3.4 \%$ \\
$80 \%$ & 0.144 & 0.158 & 0.157 & $9.6 \%$ & $9.1 \%$ \\
$85 \%$ & 0.102 & 0.102 & 0.102 & $0.0 \%$ & $0.0 \%$ \\
$90 \%$ & 0.055 & 0.055 & 0.055 & $0.1 \%$ & $0.0 \%$ \\
\hline
\end{tabular}

Table 4. Experimental data from Feng et al. [30] and calculated values of electrical conductivity of aluminum foam using the new proposed models.

\begin{tabular}{cccccc}
\hline \multirow{2}{*}{ Porosity } & \multicolumn{2}{c}{ Electrical Conductivity $\left.\mathbf{( 1 0}^{\mathbf{6}} \mathbf{S ~ m}^{-\mathbf{1}}\right)$} & \multicolumn{2}{c}{ Absolute Relative Error } \\
\cline { 2 - 5 } & Exp. & Equation (18) & Equation (19) & Equation (18) & Equation (19) \\
\hline $68.70 \%$ & 1.855 & 1.856 & 1.855 & $0.0 \%$ & $0.0 \%$ \\
$70.50 \%$ & 1.708 & 1.710 & 1.709 & $0.1 \%$ & $0.1 \%$ \\
$71.20 \%$ & 1.664 & 1.653 & 1.653 & $0.6 \%$ & $0.7 \%$ \\
$72.70 \%$ & 1.511 & 1.534 & 1.533 & $1.5 \%$ & $1.5 \%$ \\
$73.40 \%$ & 1.482 & 1.478 & 1.478 & $0.3 \%$ & $0.3 \%$ \\
$74.20 \%$ & 1.474 & 1.415 & 1.415 & $4.0 \%$ & $4.0 \%$ \\
$75.60 \%$ & 1.293 & 1.306 & 1.307 & $1.0 \%$ & $1.0 \%$ \\
$76.40 \%$ & 1.265 & 1.245 & 1.245 & $1.6 \%$ & $1.6 \%$ \\
$77.10 \%$ & 1.153 & 1.191 & 1.192 & $3.3 \%$ & $3.3 \%$ \\
$77.90 \%$ & 1.131 & 1.130 & 1.131 & $0.0 \%$ & $0.0 \%$ \\
$79.00 \%$ & 1.106 & 1.048 & 1.048 & $5.3 \%$ & $5.2 \%$ \\
$80.50 \%$ & 0.988 & 0.937 & 0.937 & $5.2 \%$ & $5.1 \%$ \\
$81.30 \%$ & 0.853 & 0.878 & 0.879 & $2.9 \%$ & $3.0 \%$ \\
$82.90 \%$ & 0.822 & 0.763 & 0.764 & $7.2 \%$ & $7.1 \%$ \\
$84.50 \%$ & 0.639 & 0.650 & 0.651 & $1.8 \%$ & $1.9 \%$ \\
$85.00 \%$ & 0.565 & 0.616 & 0.616 & $9.0 \%$ & $9.1 \%$ \\
$86.70 \%$ & 0.500 & 0.500 & 0.500 & $0.0 \%$ & $0.0 \%$ \\
$87.10 \%$ & 0.486 & 0.473 & 0.473 & $2.6 \%$ & $2.6 \%$ \\
\hline
\end{tabular}


Table 5. Average absolute relative error from different models for different structures.

\begin{tabular}{lcccccccc}
\hline \multirow{2}{*}{ Structure } & \multicolumn{3}{c}{ Previous Models } & \multicolumn{3}{c}{ Modified Models } & \multicolumn{2}{c}{ New Models } \\
\cline { 2 - 9 } & $\begin{array}{c}\text { Equation } \\
\text { (2) }\end{array}$ & $\begin{array}{c}\text { Equation } \\
\text { (3) }\end{array}$ & $\begin{array}{c}\text { Equation } \\
\text { (4) }\end{array}$ & $\begin{array}{c}\text { Equation } \\
\mathbf{( 5 )}\end{array}$ & $\begin{array}{c}\text { Equation } \\
\mathbf{( 6 )}\end{array}$ & $\begin{array}{c}\text { Equation } \\
\text { (7) }\end{array}$ & $\begin{array}{c}\text { Equation } \\
\mathbf{( 1 8 )}\end{array}$ & $\begin{array}{c}\text { Equation } \\
\text { (19) }\end{array}$ \\
\hline $\begin{array}{l}\text { Sintered metal } \\
\text { fibre (Zhou et al.) }\end{array}$ & $16.7 \%$ & $9.6 \%$ & $15.8 \%$ & $6.1 \%$ & $3.2 \%$ & $5.8 \%$ & $2.6 \%$ & $2.5 \%$ \\
$\begin{array}{l}\text { Closed-cell metal } \\
\text { foam (Feng et al.) }\end{array}$ & $12.6 \%$ & $7.1 \%$ & $11.9 \%$ & $2.8 \%$ & $2.9 \%$ & $2.8 \%$ & $2.6 \%$ & $2.6 \%$ \\
$\begin{array}{l}\text { Open-cell metal } \\
\text { foam (Liu et al.) }\end{array}$ & $8.19 \%$ & $6.50 \%$ & $7.59 \%$ & $6.10 \%$ & $5.54 \%$ & $5.98 \%$ & $5.44 \%$ & $5.41 \%$ \\
\hline
\end{tabular}

Therefore, by looking at the results from the modified models and the new proposed models, it can be concluded that for sintered metal fibres, the presumption of having zero conductivity at a porosity of $100 \%$ does not provide accurate results. By doing so, the errors for sintered copper fibres can reach up to $30 \%$ for the range of $70 \%-90 \%$. Also, as it was expected, the critical porosity obtained by fitting the models to the experimental results for open-cell metal foam, was higher (close to unity) than that of obtained for sintered metal fibres and closed-cell metal foam. The suggested reason is that for having structural integrity for a similar structure, closed-cell metal foam requires more solid phase. The average ARE from using different models for different structures can be seen in Table 5. As it can be observed, for the sintered metal fibres, significant improvement can be gained by the modified models and even more significantly by the new proposed models. For closed-cell the improvement is moderate; and finally, for the open cell metal foam, the reduction in error is marginal and average ARE is reduced by around 1\% to 3\%. As a result, it is suggested that for open cell metal foam Equation (3) can be used, which gives less error compared to Equations (2) and (4) and the inclusion of critical porosity does not bring significant improvement. For closed cell metal foams, modified models (i.e., Equations (5)-(7)) and new suggested models (i.e., Equations (18) and (19)) provide similar accuracy and outperform models without considering critical porosity. Finally, for sintered metal fibre porous media, the newly proposed models outperform the previous models and hence are recommended to be considered for this type of porous metal.

The critical porosity at which the electrical conductivity reaches zero (i.e., the maximum porosity that is achievable to have a connected cluster of solid phased) depends on the type of the porous metal (the method by which the porous metal is manufactured). The highest amount of porosity in porous metals can be achieved in metal foams, specifically open-cell metal foams. Metal foams typically have larger pore size compared to that of sintered metal fibres or powders. Larger pores mean higher void space ratio to solid phase. Also, in metal foams that are manufactured from molten metal, the solid phase is uniform and there is no contact resistance in the structure. Additionally, open-cell metal foams can provide higher porosities in comparison to the closed-cell metal foams as the walls (solid phase) are non-existent in open-cells and only struts are present to form a cell. On the other hand, sintered porous metals, are formed by means of pressure at high temperatures. This puts a limit on the maximum porosity achievable. Additionally, as the sintering depends on the temperature, pressure, and the duration, the electrical conductivity depends on these factors $[40,48]$. These factors affect the contact between the metal fibres or powders and hence the overall electrical conductivity. As a result, the critical porosity, has a more significant effect on the accuracy of the models for porous metals formed by sintering, followed by closed-cell metal foams, and finally less impact on the open-cell metal foams. This is also evident in the results by fitting the models and the critical porosity for the open-cell foam was obtained to be close to one, whereas for sintered metal fibres, this value was $\sim 95 \%$.

In order, to find the validity of the models for other cases of closed-cell metal foams the models are fitted to additional data from the literature. For metal foams, the data from Feng et al. [30], Sevostianov et al. [49], Kim et al. [50] and Kovacik et al. [51] are used. After fitting the data to these models, the coefficients are obtained as presented in Table 5 . The critical porosity and the tortuosity coefficient are similar for different datasets. The value of $K$ (manufacturing effects) is close for the 
three of the datasets $([30,50,51]$, However, $K$ for the data from Sevostianov et al. [49] is slightly lower. The value of $K$ is expected to vary between different datasets provided by different research groups as it depends on several factors and the complex interaction between them such as impurities and manufacturing methods implemented. If a $K$ value based on these data is applied to a new dataset, a higher error could potentially arise due to the effect of aforementioned parameters. Therefore, it is suggested for new porous metals, few measurements of the electrical conductivity of samples with different porosities to be experimentally measured (e.g., two different porosities). Subsequently, the value of $K$ can be determined based on those values to minimise the error and predict the electrical conductivity of the porous metal at different porosities by the model. This allows the prediction of the conductivity for a wide range of porosity that otherwise needs to be measured individually and samples with different porosities are required to be manufactured that are not practical in many circumstances. This will help in modelling of devices implementing such materials, where electrical conductivity is required such as fuel cells and electrolysers.

Also, if the value of $K$ for closed metal foams (Table 6) is compared the value for sintered metal fibres (experimental data from Zhou et al. [40]), 0.03, it is evident that the value of $K$ is significantly higher for closed-cell metal foams as expected. This can be explained by the fact that in metal foams, the solid phase can be considered one connected piece, whereas in sintered porous metals, there are numerous connections points between the particles adding to the overall resistance (i.e., lower conductivity) resulting in a lower value of $K$. In other words, the value of $K$ represents the deviation from ideal conditions.

Table 6. Coefficient of the new models: Equations (18) and (19), for closed-cell metal foams.

\begin{tabular}{lccccccc}
\hline \multirow{2}{*}{ Data Sets } & \multicolumn{3}{c}{ Equation (18) } & \multicolumn{4}{c}{ Equation (19) } \\
\cline { 2 - 8 } & $\boldsymbol{K}$ & $\mathcal{\varepsilon}_{\boldsymbol{c}}$ & $\boldsymbol{\alpha}$ & $\boldsymbol{K}$ & $\mathcal{\varepsilon}_{\boldsymbol{c}}$ & $\boldsymbol{P}$ \\
\hline Feng et al. & 0.80 & & & 0.81 & & \\
Kovacik et al. & 0.76 & & & 0.77 & 0.97 & 0.37 \\
Sevostianov et al. & 0.67 & 0.99 & 0.32 & 0.67 & & \\
Kim et al. & 0.78 & & & 0.79 & & \\
\hline
\end{tabular}

\section{Conclusions}

The effect of porosity on the electrical conductivity of different types of porous metals was investigated through different existing semi-empirical models and the applicability of these models was evaluated for open and closed cell metal foams as well as metal fibres. These models are proposed based on metal foams; that is why they can represent the electrical conductivity of open-cell metal foams with low errors for porosities over $80 \%$. However, the error increases for closed-cell metal foams. For sintered metal fibres the error is even more considerable as it can be as high as $30 \%$. These existing models that are predicting the conductivity to be zero at $100 \%$ porosity do not match the experimental measurements. In practice, porous metals with porosities close to $100 \%$ cannot be produced, especially if sintering technology is used, and the maximum achievable porosity is the tap porosity. Therefore, the critical porosity is introduced in the models. This means that the electrical conductivity should reach the value of zero at a porosity lower than $100 \%$ (i.e., critical porosity). This modification improves the models predictions significantly (i.e., reduces the error of the models). Moreover, two new empirical models (Equations (18) and (19)) based on mixture model, tortuosity, and critical porosity were proposed for sintered metal fibres. Using these models, the critical porosity (the porosity at which the electrical conductivity becomes zero) was estimated to be $\sim 95 \%$ for sintered metal fibres rather than $100 \%$. These models offered more accuracy and lower errors compared to previous models, especially for sintered metal fibres. The model proposed by Liu et al. [34,39], Equation (3), outperforms the other models, Equations (2) and (4), and its modified model, Equation (6) performed better than the modified version of the other models. 
The two new models (Equations (18) and (19)) were also fitted to more experimental data from literature, in order to investigate if the values for the coefficients can be generalised based on the type of the porous metal. As currently, most of the data available in the literature are for closed-cell metal foams; hence, the present study was only carried out for this type of porous metals. It was found that the values of critical porosity and tortuosity coefficient can be applied to different datasets, however, the coefficient considered for manufacturing effect, $\mathrm{K}$, is different for one of the datasets while the difference for other datasets are not significant.

In summary, it is suggested that for high porosity sintered metal fibres, which are usually used in electrochemical devices, the critical porosity (i.e., the maximum possible physical porosity) should be considered as it noticeably affects the accuracy of the models. By using the modified models and the new models, the average ARE was reduced from as high as $16.7 \%$ to as low as $2.5 \%$. In addition, the maximum ARE in the unmodified models is from $17 \%$ to $31.8 \%$, which was reduced to $9.1 \%$ to $18.3 \%$ by modifications and introduction of new models. Considering that these findings were based on the porous metals with porosities above $70 \%$, further investigation is still required to check the applicability of these formulas for lower ranges of porosities, i.e., lower than $50 \%$. It is worthwhile to mention that as contact resistance can significantly affect the ohmic losses in electrochemical devices the effect of porosity on contact resistance is recommended to be investigated separately.

Author Contributions: Conceptualisation, R.O.; methodology, R.O.; literature review, R.O.; validation, R.O. and B.S.; formal analysis, R.O. and B.S.; investigation, R.O. and B.S.; writing-original and draft preparation, R.O. writing-review and editing, R.O. and B.S.; project supervision, B.S.; and project administration R.O.

Funding: This research received no external funding.

Acknowledgments: The authors gratefully acknowledge the support through the provision of an Australian Government Research Training Program Scholarship by RMIT University.

Conflicts of Interest: The authors declare no conflict of interest.

\section{References}

1. Liu, P.S.; Chen, G.F. Porous Materials: Processing and Applications; Butterworth-Heinemann: Boston, MA, USA, 2014. [CrossRef]

2. Dukhan, N. Metal Foams: Fundamentals and Applications; Destech Publications: Lancaster, PA, USA, 2013. [CrossRef]

3. Lefebvre, L.P.; Banhart, J.; Dunand, D.C. Porous Metals and Metallic Foams: Current Status and Recent Developments. Adv. Eng. Mater. 2008, 10, 775-787. [CrossRef]

4. Sajid Hossain, M.; Shabani, B. Metal foams application to enhance cooling of open cathode polymer electrolyte membrane fuel cells. J. Power Sources 2015, 295, 275-291. [CrossRef]

5. Gabbasa, M.; Sopian, K.; Fudholi, A.; Asim, N. A review of unitized regenerative fuel cell stack: Material, design and research achievements. Int. J. Hydrog. Energy 2014, 39, 17765-17778. [CrossRef]

6. Carmo, M.; Fritz, D.L.; Mergel, J.; Stolten, D. A comprehensive review on PEM water electrolysis. Int. J. Hydrog. Energy 2013, 38, 4901-4934. [CrossRef]

7. Sajid Hossain, M.; Shabani, B. Air flow through confined metal foam passage: Experimental investigation and mathematical modelling. Exp. Therm. Fluid Sci. 2018, 99, 13-25. [CrossRef]

8. Sajid Hossain, M.; Shabani, B. Experimental study on confined metal foam flow passage as compact heat exchanger surface. Int. Commun. Heat Mass Transf. 2018, 98, 286-296. [CrossRef]

9. Liu, P.S.; Chen, G.F. Chapter Three-Application of Porous Metals. In Porous Materials; Chen, P.S.L.F., Ed.; Butterworth-Heinemann: Boston, MA, USA, 2014. [CrossRef]

10. Yuan, W.; Tang, Y.; Yang, X.; Wan, Z. Porous metal materials for polymer electrolyte membrane fuel cells-A review. Appl. Energy 2012, 94, 309-329. [CrossRef]

11. Arisetty, S.; Prasad, A.K.; Advani, S.G. Metal foams as flow field and gas diffusion layer in direct methanol fuel cells. J. Power Sources 2007, 165, 49-57. [CrossRef]

12. Tang, H.P.; Wang, J.; Qian, M. 28-Porous titanium structures and applications. In Titanium Powder Metallurgy; Qian, M., Froes, F.H., Eds.; Butterworth-Heinemann: Boston, MA, USA, 2015. [CrossRef] 
13. Güden, M.; Çelik, E.; Hızal, A.; Altındiş, M.; Çetiner, S. Effects of compaction pressure and particle shape on the porosity and compression mechanical properties of sintered Ti6Al4V powder compacts for hard tissue implantation. J. Biomed. Mater. Res. Part B Appl. Biomater. 2008, 85B, 547-555. [CrossRef] [PubMed]

14. Grootenhuis, P.; Powell, R.W.; Tye, R.P. Thermal and Electrical Conductivity of Porous Metals made by Powder Metallurgy Methods. Proc. Phys. Soc. Sect. B 1952, 65, 502. [CrossRef]

15. Grigoriev, S.A.; Millet, P.; Volobuev, S.A.; Fateev, V.N. Optimization of porous current collectors for PEM water electrolysers. Int. J. Hydrog. Energy 2009, 34, 4968-4973. [CrossRef]

16. Hwang, C.M.; Ishida, M.; Ito, H.; Maeda, T.; Nakano, A.; Hasegawa, Y.; Yokoi, N.; Kato, A.; Yoshida, T. Influence of properties of gas diffusion layers on the performance of polymer electrolyte-based unitized reversible fuel cells. Int. J. Hydrog. Energy 2011, 36, 1740-1753. [CrossRef]

17. Omrani, R.; Shabani, B. Review of gas diffusion layer for proton exchange membrane-based technologies with a focus on unitised regenerative fuel cells. Int. J. Hydrog. Energy 2019, 44, 3834-3860. [CrossRef]

18. Lin, H.-H.; Cheng, C.-H.; Soong, C.-Y.; Chen, F.; Yan, W.-M. Optimization of key parameters in the proton exchange membrane fuel cell. J. Power Sources 2006, 162, 246-254. [CrossRef]

19. Cheema, T.A.; Zaidi, S.M.J.; Rahman, S.U. Three dimensional numerical investigations for the effects of gas diffusion layer on PEM fuel cell performance. Renew. Energy 2011, 36, 529-535. [CrossRef]

20. Maslan, N.H.; Gau, M.M.; Masdar, M.S.; Rosli, M.I. Simulation of porosity and PTFE content in gas diffusion layer on proton exchange membrane fuel cell performance. J. Eng. Sci. Technol. 2016, 11, 85-95.

21. Larbi, B.; Alimi, W.; Chouikh, R.; Guizani, A. Effect of porosity and pressure on the PEM fuel cell performance. Int. J. Hydrog. Energy 2013, 38, 8542-8549. [CrossRef]

22. Sahraoui, M.; Kharrat, C.; Halouani, K. Two-dimensional modeling of electrochemical and transport phenomena in the porous structures of a PEMFC. Int. J. Hydrog. Energy 2009, 34, 3091-3103. [CrossRef]

23. Mason, T.J.; Millichamp, J.; Shearing, P.R.; Brett, D.J.L. A study of the effect of compression on the performance of polymer electrolyte fuel cells using electrochemical impedance spectroscopy and dimensional change analysis. Int. J. Hydrog. Energy 2013, 38, 7414-7422. [CrossRef]

24. Omrani, R.; Shabani, B. Gas diffusion layer modifications and treatments for improving the performance of proton exchange membrane fuel cells and electrolysers: A review. Int. J. Hydrog. Energy 2017, 42, 28515-28536. [CrossRef]

25. Ye, D.; Gauthier, E.; Benziger, J.B.; Pan, M. Bulk and contact resistances of gas diffusion layers in proton exchange membrane fuel cells. J. Power Sources 2014, 256, 449-456. [CrossRef]

26. Xing, X.Q.; Lum, K.W.; Poh, H.J.; Wu, Y.L. Optimization of assembly clamping pressure on performance of proton-exchange membrane fuel cells. J. Power Sources 2010, 195, 62-68. [CrossRef]

27. Mason, T.J.; Millichamp, J.; Neville, T.P.; El-kharouf, A.; Pollet, B.G.; Brett, D.J.L. Effect of clamping pressure on ohmic resistance and compression of gas diffusion layers for polymer electrolyte fuel cells. J. Power Sources 2012, 219, 52-59. [CrossRef]

28. Obayopo, S.O.; Bello-Ochende, T.; Meyer, J.P. Three-dimensional optimisation of a fuel gas channel of a proton exchange membrane fuel cell for maximum current density. Int. J. Energy Res. 2013, 37, 228-241. [CrossRef]

29. Yan, W.M.; Soong, C.Y.; Chen, F.; Chu, H.S. Effects of flow distributor geometry and diffusion layer porosity on reactant gas transport and performance of proton exchange membrane fuel cells. J. Power Sources 2004, 125, 27-39. [CrossRef]

30. Feng, Y.; Zheng, H.; Zhu, Z.; Zu, F. The microstructure and electrical conductivity of aluminum alloy foams. Mater. Chem. Phys. 2003, 78, 196-201. [CrossRef]

31. Morgan, J.M.; Datta, R. Understanding the gas diffusion layer in proton exchange membrane fuel cells. I. How its structural characteristics affect diffusion and performance. J. Power Sources 2014, 251, 269-278. [CrossRef]

32. Netwall, C.J.; Gould, B.D.; Rodgers, J.A.; Nasello, N.J.; Swider-Lyons, K.E. Decreasing contact resistance in proton-exchange membrane fuel cells with metal bipolar plates. J. Power Sources 2013, 227, 137-144. [CrossRef]

33. Langlois, S.; Coeuret, F. Flow-through and flow-by porous electrodes of nickel foam. I. Material characterization. J. Appl. Electrochem. 1989, 19, 43-50. [CrossRef]

34. Liu, P.S.; Li, T.F.; Fu, C. Relationship between electrical resistivity and porosity for porous metals. Mater. Sci. Eng. A 1999, 268, 208-215. [CrossRef] 
35. Dharmasena, K.P.; Wadley, H.N.G. Electrical Conductivity of Open-cell Metal Foams. J. Mater. Res. 2002, 17, 625-631. [CrossRef]

36. Hakamada, M.; Kuromura, T.; Chen, Y.; Kusuda, H.; Mabuchi, M. Influence of Porosity and Pore Size on Electrical Resistivity of Porous Aluminum Produced by Spacer Method. Mater. Trans. 2007, 48, 32-36. [CrossRef]

37. Huang, P.Y. Principles of Powder Metallurgy; Metallurgical Industry Press: Beijing, China, 1997.

38. Liu, P.; Fu, C.; Li, T. Calculation formula for apparent electrical resistivity of high porosity metal materials. Sci. China Ser. E-Technol. Sci. 1999, 42, 294-301. [CrossRef]

39. Liu, P.S.; Liang, K.M. Evaluating electrical resistivity for high porosity metals. Mater. Sci. Technol. 2000, 16, 341-343. [CrossRef]

40. Zhou, W.; Tang, Y.; Song, R.; Jiang, L.; Hui, K.S.; Hui, K.N. Characterization of electrical conductivity of porous metal fiber sintered sheet using four-point probe method. Mater. Des. 2012, 37, 161-165. [CrossRef]

41. Sheng, M.; Cahela, D.R.; Yang, H.; Gonzalez, C.F.; Yantz, W.R.; Harris, D.K.; Tatarchuk, B.J. Effective thermal conductivity and junction factor for sintered microfibrous materials. Int. J. Heat Mass Transf. 2013, 56, 10-19. [CrossRef]

42. Huang, X.; Zhou, Q.; Liu, J.; Zhao, Y.; Zhou, W.; Deng, D. 3D stochastic modeling, simulation and analysis of effective thermal conductivity in fibrous media. Powder Technol. 2017, 320, 397-404. [CrossRef]

43. Goodall, R.; Weber, L.; Mortensen, A. The electrical conductivity of microcellular metals. J. Appl. Phys. 2006, 100, 044912. [CrossRef]

44. Li, L.; Chung, D.D.L. Electrical and mechanical properties of electrically conductive polyethersulfone composites. Composites 1994, 25, 215-224. [CrossRef]

45. Ebner, M.; Wood, V. Tool for Tortuosity Estimation in Lithium Ion Battery Porous Electrodes. J. Electrochem. Soc. 2015, 162, A3064-A3070. [CrossRef]

46. Farmer, J.; Duong, B.; Seraphin, S.; Shimpalee, S.; Martínez-Rodríguez, M.J.; Van Zee, J.W. Assessing porosity of proton exchange membrane fuel cell gas diffusion layers by scanning electron microscope image analysis. J. Power Sources 2012, 197, 1-11. [CrossRef]

47. Saomoto, H.; Katagiri, J. Direct comparison of hydraulic tortuosity and electric tortuosity based on finite element analysis. Theor. Appl. Mech. Lett. 2015. [CrossRef]

48. Kostornov, A.G.; Shevchuk, M.S.; Lezhenin, F.F.; Fedorchenko, I.M. An experimental investigation into the thermal and electrical conductivities of metal fiber materials. Sov. Powder Metall. Metal Ceram. 1977, 16, 194-197. [CrossRef]

49. Sevostianov, I.; Kováčik, J.; Simančík, F. Elastic and electric properties of closed-cell aluminum foams: Cross-property connection. Mater. Sci. Eng. A 2006, 420, 87-99. [CrossRef]

50. Kim, A.; Hasan, M.A.; Nahm, S.H.; Cho, S.S. Evaluation of compressive mechanical properties of Al-foams using electrical conductivity. Comp. Struct. 2005, 71, 191-198. [CrossRef]

51. Kováčik, J.; Simančík, F. Aluminium foam-Modulus of elasticity and electrical conductivity according to percolation theory. Scr. Mater. 1998, 39, 239-246. [CrossRef]

(C) 2019 by the authors. Licensee MDPI, Basel, Switzerland. This article is an open access article distributed under the terms and conditions of the Creative Commons Attribution (CC BY) license (http://creativecommons.org/licenses/by/4.0/). 